\title{
The Transfer of Nicotine from Nicotine Salts to Mainstream Smoke*
}

\author{
by
}

T.A. Perfetti, A.B. Norman, B.M. Gordon, W.M. Coleman, III, W.T. Morgan, G.M. Dull and C.W. Miller

\author{
R.J. Reynolds Tobacco Company \\ P.O. Box 1487 \\ Winston-Salem, NC 27102-1487
}

\section{SUMMARY}

Transfer of nicotine to mainstream smoke was measured for Reference cigarettes made with the addition of 20-40 $\mathrm{mg}$ of seven different nicotine salts, $d$ - and $l$-nicotine and $N$-formylnornicotine. Regression analysis of the nicotine yields from these cigarettes as a function of the nicotine content of the tobacco rods indicated an average nicotine transfer efficiency (17.5\%), similar to that found for a separate series of cigarettes made with single-grade tobacco materials (16.2\%). Analysis of the enantiomeric purity of the smoke nicotine from the cigarettes made with added nicotine salts and neat nicotine showed no evidence of conversion between $l$-and $d$-nicotine during the smoking process. The cigarette made with added $N$ formylnornicotine showed no evidence of additional nicotine transfer attributable to reduction of this compound to nicotine. A third series of cigarettes were made with varying levels of $d$ - and $l$-nicotine added to a tobacco blend and to reconstituted tobacco to further investigate transfer efficiency of the enantiomers. Regression analysis indicated no statistically significant difference between transfer efficiencies of $d$ - and $l$-nicotine. These results suggest that nicotine salts and $d$-and $l$-nicotine transfer to smoke at the same efficiency. However, transfer efficiency of either compound was lower when applied to reconstituted tobacco $(9.7 \%)$ than when applied to the Reference tobacco blend (15.3\%). The thermal stabilities of nicotine salts have little bearing on efficiency of transfer to smoke or on racemization between $d$ - and $l$ nicotine. Formation of $d$-nicotine in mainstream smoke via reduction of $N^{\prime}$-formylnornicotine does not appear to occur. [Beitr. Tabakforsch. Int. 19 (2000) 141-160]

\section{ZUSAMMENFASSUNG}

Es wurde der Übergang des Nikotins in den Hauptstromrauch von Referenzcigaretten gemessen, denen $20-40 \mathrm{mg}$ sieben verschiedener Nikotinsalze, $d$ - und $l$-Nikotin und $N$-Formylnornikotin zugesetzt wurden. Eine Regressionsanalyse des Nikotingehalts dieser Cigaretten als Funktion des Nikotingehalts des Tabakstranges zeigte eine durchschnittliche Effizienz des Nikotinübergangs $(17,5 \%)$, die ähnlich war wie bei einer speziellen Serie von Cigaretten, die aus Tabaken eines Grades hergestellt wurden (16,2\%). Eine Analyse der Reinheit bezüglich der Enantiomere des Nikotins im Rauch von Cigaretten, denen Nikotinsalze zugesetzt wurden und reinem Nikotin erbrachte keinen Hinweis auf eine Umwandlung zwischen $d$ - und $l$-Nikotin während des Rauchvorgangs. Bei der Cigarette, der $N$ '-Formylnornikotin zugesetzt wurde, gab es keinen Hinweis auf einen zusätzlichen Nikotinübergang, der auf die Reduktion dieser Verbindung zum Nikotin zurückgeführt werden könnte. Bei einer dritten Serie von Cigaretten wurden einem Tabakgemisch und Tabakfolie unterschiedliche Mengen and-und $l$-Nikotin zugesetzt, um die Effizienz des Übergangs der Enantiomere weitergehend zu untersuchen. Die Regressionsanalyse zeigte keinen statistisch signifikanten Unterschied in der Effizienz des Übergangs zwischen $d$ - und $l$-Nikotin. Diese Ergebnisse lassen darauf schließen, dass Nikotinsalze sowie $d$ - und $l$-Nikotin im gleichen Ausmaß in den Rauch übergehen. Die Effizenz des Übergangs war jedoch bei beiden Verbindungen niedriger, wenn sie Tabakfolie $(9,7 \%)$ als wenn sie der Tabakmischung der Referenzcigaretten $(15,3 \%)$ zugesetzt wurden. Die thermische Stabilität der Nikotinsalze hat nur geringen Einfluß auf die Effi- 
zienz des Übergangs in den Rauch oder auf die Razemisierung zwischen $d$ - und $l$-Nikotin. Eine Bildung von $d$ Nikotin im Hauptstromrauch durch die Reduktion von $N$-Formylnornikotin scheint nicht stattzufinden. [Beitr. Tabakforsch. Int. 19 (2000) 141-160]

\section{RESUME}

Le transfert de la nicotine vers la fumée du courant principal des cigarettes de référence, auxquelles étaient apportés $20-40 \mathrm{mg}$ de sept différents sels de nicotine, $d$ et $l$-nicotine et $N$-formylnornicotine, a été mesuré. L'analyse de régression du rendement en nicotine de ces cigarettes en fonction de la teneur en nicotine du boudin de tabac indique un taux de transfert moyen de la nicotine de l'ordre de $17.5 \%$ correspondant au taux obtenu avec une série de cigarettes confectionnées avec un grade unique de tabac (16.2\%). L'analyse de la pureté énantiomérique de la nicotine dans la fumée des cigarettes, auxquelles étaient apportés un sel de nicotine et de la nicotine pure, n'a pas donné d'indication d'une conversion racémique du $l$ - et du $d$-nicotine au cours du fumage. La cigarette à laquelle était apporté de la $N^{\prime}$-formylnornicotine n'a pas donné d'indication d'un transfert supplémentaire de la nicotine qui pourrait être attribué à la réduction de ce composé en nicotine. Une troisième série de cigarettes a été confectionnée avec des quantités différentes en $d$ - et $l$-nicotine ajoutées au mélange de tabac et au tabac reconstitué, afin de préciser l'efficacité du transfert des énantiomères. L'analyse de régression a montré que la différence du taux de transfert entre $d$ - et $l$ nicotine n'était pas statistiquement significative. Ces résultats suggèrent que les sels de nicotine et la $d$ - et $l$ nicotine sont transférés vers la fumée avec une efficacité équivalente. Cependant, l'efficacité du transfert de ces composés est moindre dans le cas où ils sont apportés au tabac reconstitué $(9,7 \%)$ que lorsqu'ils sont apportés au mélange du tabac de référence (15.3\%). La stabilité thermique des sels de nicotine a peu de rapport avec l'efficacité du transfert vers la fumée ou la racémisation de la $d$-et $l$-nicotine. La formation de la $d$-nicotine dans la fumée du courant principal par la réduction du $N^{\prime}$ formylnornicotine n'a vraisemblablement pas lieu. [Beitr. Tabakforsch. Int. 19 (2000) 141-160]

\section{INTRODUCTION}

Nearly all the nicotine in tobacco is in the form of nicotine salts $(1,17)$. The amount of tobacco nicotine (per cigarette) in a commercial blended cigarette is usually 8-15 mg. In some single grade cigarettes and in some Reference cigarettes the range can be much wider $(30,34$, $35)$. It has been reported that nicotine transfers to mainstream smoke at an efficiency of approximately $10 \%$ for filtered products $(2,3)$ and can be as much as $22 \%$ for Oriental non-filtered cigarettes (14). Nicotine transfer efficiencies are calculated values, which are obtained from mainstream smoke nicotine yields divided by the total nicotine available in the portions of the tobacco rods that are consumed. Variations in nicotine transfer efficiencies or more appropriately, apparent nicotine transfer efficiencies, calculated in this manner reflect differences in the amount of tobacco burnt during puffing. Elucidation of the mechanisms of and factors that affect smoke generation can aid in the understanding of cigarette smoke deliveries and the modification of smoke composition (4-11). An understanding of how nicotine is transferred to smoke is important in the design of cigarette products (4). The topic of nicotine transfer has recently been reviewed by RUSTEMEIER and PIADÉ (7). The efficiency of nicotine transfer to mainstream smoke has been studied by numerous workers $(4,5,8,10,12-16,18)$. Tso and CHAPLIN (16) reported that nicotine transfer efficiencies for cigarettes made with low stalk-position flue-cured tobacco were lower than those for cigarettes made with high stalk-position flue-cured tobacco. These workers also reported (16) nicotine transfer efficiencies for cigarettes made with several cultivars. DAVIS et al. (12) reported transfer efficiencies of endogenous and exogenous nicotine, nornicotine, anabasine, and anatabine. In 1975, THORNTON and MASSEY (15), and in 1981, BETTS (18), reported effects of added tobacco sugars on nicotine transfer efficiencies and "smoke $\mathrm{pH}$ ", respectively.

Radioisotopic experiments with unprotonated (neat) nicotine, nicotine salts and radioactive tobaccos (having endogenous uniformly $(\mathrm{U})$ labeled nicotine) have been performed that indicated that nicotine and nicotine salts are transferred to mainstream and sidestream smoke with essentially the same efficiency as naturally occurring nicotine in tobacco $(4,5,8,10,19,23)$. HOUSEMAN (13) conducted studies on the transference of $d-\left[2{ }^{3}-{ }^{14} \mathrm{C}\right]$ nicotine di-p-toluoyltartrate added to cigarettes by syringe injection. He found that the specific activity of the alkaloids transferred to smoke $\left(d-\left[2,-{ }^{14} C\right]\right.$ nicotine $)$ was slightly higher than the specific activity of the tobacco (l-nicotine). HOUSEMAN (13) and JeNKINS and COMES in a review of the HOUSEMAN data (19) concluded that the smoke transference of exogenous $d$ - and $l$-nicotine were similar, but not the same.

In 1983, PERFETTI (17) reported on the varied structures and thermal characteristics of a wide variety of nicotine salts. He noted that the different nicotine salts had a wide range of melting points and decomposition temperatures. The thermal stability of the nicotine salts can vary greatly. SEEMAN et al. (25) reported that different nicotine salts liberate nicotine over different temperature ranges (110-125 ${ }^{\circ} \mathrm{C}$ and $\left.160-210^{\circ} \mathrm{C}\right)$ under specific thermogravimetry (TG)/differential thermal analysis (DTA)/mass spectrometry (MS) conditions of the determination (25). Some nicotine salts, like nicotine silicotungstic acid are thermally stable crystalline solids with melting points over $300^{\circ} \mathrm{C}(17)$. Other salts, like nicotine acetate, are comparatively less thermally stable. For example, nicotine acetate, a light yellow odorless oil when initially prepared, began to decompose to a light brown oil and give off the odor of 
acetic acid within a few days at room temperature (17). This compound would be considered less thermally stable than nicotine salicylate, a crystalline solid (m.p. = 116-117 ${ }^{\circ} \mathrm{C}$ ), or nicotine alginate, an amorphous solid (decomposed at temperature $>160^{\circ} \mathrm{C}$ ) (17). Nicotine alginate, when initially prepared, is an amorphous tan solid that after months of standing at room temperature remains unchanged in color, odorless, and gives the same analysis results for percent nicotine as it did initially. SEEMAN et al. have recently presented work on the thermal transfer of nicotine and nicotine salts to the gas phase (25). SEEMAN et al. concluded that neat nicotine and salts of nicotine with carboxylic acids (acetic, malic and tartaric acids) present in tobacco would transfer nicotine to mainstream smoke with comparable efficiencies during the smoking process. STEVENS and BORGERDING (26), in a study on the fate of nicotine in tobacco and smoke, reported that $61 \%$ of nicotine- $d_{4}$ injected into cigarettes transferred as intact nicotine into the mainstream and sidestream smoke. In the same experiment, they were able to recover nearly $79 \%$ of the tobacco nicotine when they took into account the nicotine in the cigarette butt and the nicotine in the total smoke collection chamber.

Although the overall transfer efficiency of nicotine from tobacco to mainstream and sidestream smoke (nicotine fate experiments) is dependent on the type and chemical composition of tobaccos employed in the cigarette, the cigarette configuration, and the smoking parameters, the published recovery of intact nicotine in mainstream and sidestream smoke ranges between $46-61 \%(26,27)$. The question of whether nicotine salts of varying thermal stability and of different enantiomeric forms ( $d$ - vs. $l$ nicotine) transfer nicotine to mainstream smoke at different efficiencies has not been thoroughly addressed in the literature.

This study reports findings on the apparent mainstream nicotine transfer efficiency from University of Kentucky Reference cigarettes (2R1), where a variety of nicotine salts having different thermal stabilities were applied to tobacco. This report also presents data on the nicotine transfer efficiency for a separate series of single grade cigarettes. The nicotine transfer efficiencies for the enantiomers of nicotine are presented in a third series of cigarettes where $d$-and $l$-nicotine were added to two different cigarettes at different levels. Finally, this report presents results on experiments designed to test the hypothesis for formation of $d$-nicotine in mainstream tobacco smoke from exogenously applied $d, l-N$-formylnornicotine.

\section{EXPERIMENTAL}

Cigarettes - Reagents - Methods

Reference cigarettes with and without additives

The Reference cigarette 2R1 was purchased from the University of Kentucky Tobacco and Health Research Institute (Lexington, KY). These cigarettes have been de- scribed in detail by DiANA et al. (30). Ten $85-\mathrm{mm}$ nonfiltered cigarettes were prepared with added nicotine salts, $l$-nicotine or $d$-nicotine and $N$-formylnornicotine. Properties of the nicotine salts are presented in Table 1 . The 2R1 Reference cigarette was used as a control. Cigarettes with neat $l$ - or $d$-nicotine and nicotine acetate were prepared by injection of the appropriate nicotine compound into 2R1 Reference cigarettes. Cigarettes with nicotine salicylate, nicotine ditartrate dihydrate (nicotine tartrate) and $d, l-N$-formylnornicotine were prepared by injection of aqueous solutions of these nicotine salts into 2R1 Reference cigarettes. Cigarettes with nicotine alginate, nicotine tannate, nicotine galacturonate, or nicotine di-ptoluoyltartrate were prepared by removing tobacco from the $2 \mathrm{R} 1$ cigarettes, and casing a solution of propylene glycol-water-nicotine salt onto the $2 \mathrm{R} 1$ tobacco. The cased tobaccos containing each nicotine salt were conditioned to 12 percent moisture and cigarettes were made with a Premier Supermatic Cigarette Machine (The Central Tobacco Manufacturing Company, Ltd., Canada) using the cigarette wrappers from 2R1 cigarettes. Cigarettes were selected to approximately the same weight as the 2R1 Reference cigarettes. All cigarettes of this series were smoked at a butt length of $23 \mathrm{~mm}$ (i.e., $62 \mathrm{~mm}$ of each rod was consumed during smoking.)

\section{Single grade cigarettes}

Non-filtered cigarettes (70-mm tobacco rod length, 24.8 $\mathrm{mm}$ circumference) were made from each of ten tobacco types. Tobacco types were designated as FC1, FC2, B1, B2, O, E, STEM1, TS1, TS2 and TS3. Descriptions of these materials are shown in Table 2. The paper-type reconstituted tobacco sheet (RTS) used in this study was previously described by PERFETTI and COLEMAN (34). TS1, TS2, and TS3 correspond to Samples A, B, and C (34). The stem and leaf content of the RTS samples were $62 \%$ and $38 \%$, respectively.

The tobacco was cut to a standard width (28 cuts per inch) without casing or added glycerin. Cigarettes for each single grade of tobacco were made to approximately constant tobacco rod firmness and rod weights. The cigarette rod firmness and weights were allowed to vary across tobacco types. The cigarette paper employed in this series of test products was obtained from Ecusta Division of P.H. Glatfelter (Pisgah Forest, NC) and had a CORESTA porosity of $24(\mathrm{~cm} / \mathrm{min})$ and contained $0.55 \%$ citrate burn chemical. The citrate burn chemical was a mixture of sodium and potassium citrates. Cigarettes were tipped with $25-\mathrm{mm}$ plastic straw pieces. For cigarettes of this experiment, $63 \mathrm{~mm}$ of the cigarette rod was smoked during FTC analyses.

Cigarettes prepared with d- or l-nicotine for determination of nicotine transfer efficiency

2R1 Reference cigarettes ( $85 \mathrm{~mm}$ in length) and the single grade TS1 cigarettes $(70 \mathrm{~mm}$ in length) were injected with 


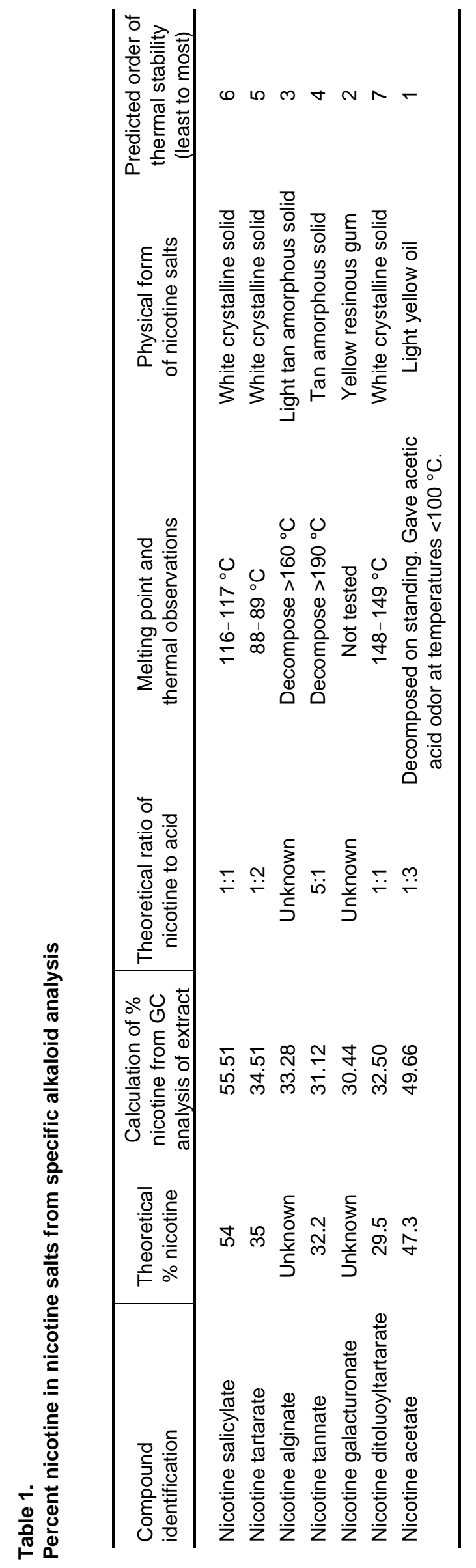


Table 2.

\section{Description of tobacco for single grade cigarettes}

\begin{tabular}{|c|c|}
\hline Code & Description \\
\hline FC1 & $\begin{array}{l}\text { Lower stalk group blend of flue-cured tobacco } \\
\text { (FC) }\end{array}$ \\
\hline FC2 & Upper stalk group blend of flue-cured tobacco \\
\hline B1 & Lower stalk group blend of Burley tobacco (B) \\
\hline $\mathrm{B} 2$ & Upper stalk group blend of Burley tobacco \\
\hline $\mathrm{O}$ & Oriental leaf $(\mathrm{O})$ \\
\hline$E$ & $\begin{array}{l}\text { Carbon dioxide }\left(\mathrm{CO}_{2}\right) \text { expanded flue-cured } \\
\text { and Burley cut filler }\end{array}$ \\
\hline STEM & Cut rolled expanded stems \\
\hline TS1 & Paper-type reconstituted tobacco sheet \\
\hline TS2 & $\begin{array}{l}\text { Heat-treated paper-type reconstituted } \\
\text { tobacco sheet }\end{array}$ \\
\hline TS3 & $\begin{array}{l}\text { Heat-treated paper-type reconstituted } \\
\text { tobacco sheet with diammonium phosphate } \\
\text { added to the extract }\end{array}$ \\
\hline
\end{tabular}

varying levels of either $d$ - or $l$-nicotine. Three levels of neat $l$-nicotine $(5,10$ and $20 \mathrm{mg})$ and three levels of neat $d$-nicotine $(5,10$ and $20 \mathrm{mg}$ ) were injected into the cigarette rods of both types of cigarettes. Tobacco nicotine analyses and FTC smoke analyses were conducted on each cigarette. The $2 \mathrm{R} 1$ and the TS1 control cigarettes were also analyzed. In this experiment, the 2R1 Reference cigarettes and the TS1 cigarettes (control and injected cigarettes) were smoked to a butt length of $23 \mathrm{~mm}$.

\section{Chemicals}

The $(S)-(-)$-isomer of nicotine (l-nicotine) was purchased from Fisher Scientific (Pittsburgh, PA). The $(R)-(+)-$ isomer $(d$-nicotine) was prepared by T. D. C. Research (Blacksburg, VA) using an established method (32), di-ptoluoyltartrate for tartaric acid in the diastereomer formation. Nicotine salicylate was purchased from Indofine Chemical (Somerville, NJ). Nicotine di-p-toluoyltartrate (nicotine ditoluoyltartrate) was purchased from ICN (Costa Mesa, CA). Nicotine ditartrate dihydrate (nicotine tartrate) was purchased from Fisher Scientific (Pittsburgh, PA). The nicotine isomers and salts were used as received. Acetic acid, alginic acid, tannic acid and D-(+)-galacturonic acid were purchased from Fisher Scientific (Pittsburgh, PA) and used as received for the preparation of the nicotine salts. $d, l$-Nornicotine and formic acid were purchased from Sigma (St. Louis, MO). Standard solutions for chromatography were prepared in methylene chloride (Burdick and Jackson, Muskegon, MI). All other reagents and solvents were purchased from Fisher Scientific (Pittsburgh, PA) and used as received.

\section{Preparation of nicotine salts}

Nicotine acetate and nicotine tannate salts were prepared by the methods described by PERFETTI (17). Results of chemical analyses (infrared spectroscopy (IR), nuclear magnetic resonance (NMR), m.p., nicotine content) performed on these salts were nearly identical to those previously published (17). Nicotine alginate and nicotine galacturonate were prepared by an adaptation of the method of PERKINS and BALE (28) used for the preparation of nicotine alginate and nicotine pectinate. The chemical and physical properties of the nicotine alginate salt prepared for this study were nearly identical to that previously published (17). The nicotine galacturonate synthesized was a clear yellow viscous gum, which was presumably a hydrate of the desired salt. Both the nicotine galacturonate and the nicotine alginate salts contained approximately $28 \%$ nicotine.

\section{Preparation of $\mathrm{N}$ '-formylnornicotine}

The synthesis of $N$-formylnornicotine was similar to that described by BURTON, ANDERSEN, FLEMING and WALTON (41). Thus, under a nitrogen atmosphere, a solution of nornicotine $(0.2269 \mathrm{~g}, 1.531 \mathrm{mmol}$, Sigma, approximately $98 \%)$ in formic acid $(4 \mathrm{~mL}, 106.0 \mathrm{mmol}$, Sigma, approximately 99\%) was heated under reflux at $120-122^{\circ} \mathrm{C}$ (oil bath temperature) for $20.5 \mathrm{~h}$. The lightyellow solution was cooled using an ice-water bath, basified to $\mathrm{pH} 11-12$ ( $\mathrm{pH}$ paper) with $10 \%$ aqueous sodium hydroxide solution $(10 \mathrm{~mL})$, diluted with saturated aqueous sodium chloride solution $(4 \mathrm{~mL})$ and extracted with diethyl ether $(8 \times 15 \mathrm{~mL})$. The combined ether extracts were dried $\left(\mathrm{Na}_{2} \mathrm{SO}_{4}\right)$, filtered, concentrated by rotary evaporation and then briefly dried using a vacuum pump to give $0.2984 \mathrm{~g}$ of light-yellow oil. The oil was vacuum distilled using a test-tube distillation apparatus, collecting $0.1171 \mathrm{~g}$ of a colorless distillate, b.p. $65-75^{\circ} \mathrm{C}$ at $0.1 \mathrm{~mm} \mathrm{Hg}$. This distillate was shown to be nornicotine by gas chromatography-mass spectrometry (GC-MS) and ${ }^{1} \mathrm{H}$ NMR analysis. The distillation residue was collected to give $0.0638 \mathrm{~g}(23.6 \%)$ of a reddish yellow oil, with a GC-MS purity of $97.48 \%$. One impurity, nornicotine, was present at a level of $2.52 \%$. The mass spectrum of this sample of $N$-formylnornicotine was identical to that described by WARFIELD, GALLOWAY and KALLIANOS (38), and GLENN and EDWARDS III (42).

Electron impact (EI)-MS ( $\mathrm{m} / \mathrm{z}, \%$ relative intensity): 176 $\left(\mathrm{M}^{+*}, 100.0\right), 147$ (96.3), 119 (72.2), 105 (41.1), 98 (36.9), 70 (50.6), 51 (35.6), 39 (45.6), 28 (90.4).

${ }^{1} \mathrm{H} \mathrm{NMR}\left(\mathrm{CDCl}_{3}\right): \delta 8.53(2 \mathrm{H}, \mathrm{m}), 8.40$ and $8.14(1 \mathrm{H}, 2 \mathrm{~s})$, $7.53(1 \mathrm{H}$, complex m), 7.31 and $7.24(1 \mathrm{H}, 2 \mathrm{dd}, \mathrm{J}=4.7$, $1.0 \mathrm{~Hz}), 5.11$ and $4.94(1 \mathrm{H}, 2 \mathrm{dd}, \mathrm{J}=3.92 \mathrm{~Hz}), 3.70(2 \mathrm{H}$, $\mathrm{m}), 2.47(0.75 \mathrm{H}, \mathrm{m}), 1.98(3.25 \mathrm{H}, \mathrm{m})$.

\section{Instrumentation}

Separations of the enantiomers of nicotine were performed on a Hewlett Packard (HP) 6890 gas chromato- 
graph (GC) equipped with a HP 5973 mass selective detector (MSD) and a HP 6890 autoinjector. Automatic injections, $1 \mu \mathrm{L}$, were made in the split mode with a split ratio of 20 to 1 . The MSD was configured in the selected ion-monitoring mode (SIM) with $m / z$ set at 84 . The GC column was a J\&W Scientific (Folsom, CA) CyclodexB, 30 meters long, $0.25 \mathrm{~mm}$ i.d., $0.25 \mu \mathrm{m}$ film thickness fused silica column. The oven initial temperature was $50^{\circ} \mathrm{C}$. After holding at $50^{\circ} \mathrm{C}$ for $1 \mathrm{~min}$, the oven was temperature programmed to $130^{\circ} \mathrm{C}$ at $0.5^{\circ} \mathrm{C} / \mathrm{min}$, then held at $130^{\circ} \mathrm{C}$ for $30 \mathrm{~min}$. Throughout the entire chromatographic run, the flow was held constant at 2.2 $\mathrm{mL} / \mathrm{min}$. The injection port and MSD transfer line were held at $230^{\circ} \mathrm{C}(27,34,35)$.

\section{Smoke collection}

Mainstream cigarette smoke samples were obtained by smoking in accordance with accepted procedures (29) of the Federal Trade Commission (FTC). Gas chromatographic vials (1.8 $\mathrm{mL}$ volume) used in the FTC method for analysis of nicotine and water were used without further work-up for the alkaloid analyses described in this report.

\section{Analyses of nicotine salts, tobacco and smoke extractions}

Nicotine was quantitatively extracted from the nicotine salts, tobacco and smoke samples in accordance with accepted procedures (31). The presence of $d$-nicotine in the smoke and tobacco samples was confirmed by the addition of $\mu$ L quantities of a $d$-nicotine standard solution to the sample matrices and confirming the increase in abundance of $m / z=84$ at the correct retention time (34, 35). In addition, the response of $\mathrm{m} / \mathrm{z}=84$ for both isomers at equal concentrations was found to be identical.

\section{Method for statistical analysis of data}

For each cigarette tested, the apparent nicotine transfer efficiency was calculated. From these values, the sample mean and standard deviation of each series of cigarettes were calculated, and a $t$-test was used to compare the means of groups. However, such efficiency estimates can have large variances, especially when the nicotine available is low, so that variations in the mainstream smoke yield results in large swings in the efficiency estimates. Another approach is to fit a regression line with zerointercept that predicts mainstream smoke nicotine from the amount of nicotine available. The slope of this model provides an estimate of the overall average apparent nicotine transfer efficiency for the entire series of cigarettes. A graph depicting this regression line with the observed data provides a visual comparison of apparent nicotine transfer efficiency values for a series of cigarettes, especially with regard to the consistency of these values over a range of available nicotine. This method should also be used with care, since estimation of the slope in this situation is like tacking one end of the line at the origin and moving the other end to give the best fit. This means that the cigarettes with the greatest available nicotine (i.e., farthest from the origin) have the greatest influence on the estimated slope. If the data indicate that the line of best fit does not go through the origin, then forcing it to do so misrepresents the data. Thus in these analyses, we first fit a model with an intercept and test to see if the intercept is different from zero before fitting the zero-intercept model. Slopes estimated for different data series were compared using an analysis of covariance model that expressed the difference between two slopes as a model interaction term. With this parameterization, the significance test for the interaction term provides a test of the equality of slopes. When this test showed no significant differences between the slopes for two data series, a model was fit to estimate the slope for the combined data series. Otherwise no further model simplification was performed. Regression analysis and model comparisons were conducted using SAS software (SAS Institute, Cary, NC), and Microsoft Excel 97SR1 (Redmond, WA) was used for editing, formatting, and printing tables and figures.

\section{RESULTS AND DISCUSSION}

The main objective of these experiments was to determine if salts of $d$ - or $l$-nicotine of different thermal stability and neat $d$ - or $l$-nicotine, when applied to tobacco, have different apparent mainstream smoke nicotine transfer efficiencies. Another objective was to determine if these cigarettes prepared with exogenous levels of nicotine in the form of neat nicotine or nicotine salts increased the level of $d$-nicotine in mainstream smoke. Experiments were also performed to determine if exogenous $d, l-N$-formylnornicotine applied to tobacco would be reduced to $d, l$-nicotine during the smoking process or thermally decompose to $d, l$-nornicotine and react with methyl radicals to yield an enhanced level of $d$-nicotine in mainstream smoke.

The hypotheses being tested in these experiments are as follows:

- Although experiments have been performed previously to determine the apparent nicotine transfer efficiency of exogenously applied nicotine salts, there are no studies reporting the transfer efficiencies of nicotine salts having varying thermal stability. Nicotine salts of different thermal stability may transfer nicotine to mainstream smoke at different efficiencies.

- Nicotine salts that have different thermal stability melt/decompose at different temperatures. Nicotine salts that are highly thermally stable may racemize at the high temperatures within the burning cigarette to yield enhanced levels of $d$-nicotine in mainstream smoke $(34,35)$.

- $\quad N^{\prime}$-acyl alkaloids are produced during the growth and curing of tobacco. The chemical compound $N$ 'for- 
mylnornicotine is a known tobacco alkaloid $(37,38)$. The compound $d, l-N^{\prime}$-formylnornicotine can decompose in tobacco to yield $d, l$-nornicotine in mainstream smoke $(36,39,40)$. In a reducing atmosphere, such as is present behind the fire-cone of the burning cigarette, it may be possible to reduce $d, l-N^{\prime}$ formylnornicotine to nicotine. In prior work, CROOKS et al. (33) proposed that there are sufficient methyl radicals present in the tobacco smoke aerosol to react with $d$-nornicotine to produce $d$-nicotine in mainstream smoke. To test these hypotheses, $d, l-N^{\prime}$ formylnornicotine was synthesized $(38,41,42)$ and a high level (approximately $14 \mathrm{mg}$ ) of $d, l-N^{\prime}$-formylnornicotine was applied to tobacco. Cigarettes were prepared and the level of $d$-nicotine in mainstream smoke was determined.

\section{Analysis of nicotine content of nicotine salts}

Seven nicotine salts (either purchased or synthesized) were analyzed for the percentage of nicotine in each salt. Table 1 lists the seven nicotine salts, the theoretical percentage of nicotine, and the calculated percentage of nicotine from gas chromatographic analysis of the basic extract of each salt. Additionally, Table 1 lists the theoretical ratio of nicotine-to-acid in each salt, melting points and thermal observations on heating, the physical forms (liquids, gums, amorphous or crystalline solids) of the salts and a prediction of the thermal stability of each salt based on this information. The theoretical concentration of nicotine in each salt is reasonably close to the measured level of nicotine in the salts. Differences in results may be due to slight analytical errors, the formation of hydrates (known to exist in many nicotine salts) and the formation of nicotine salts with slight impurities in the starting materials. The data on physical form, melting points, observations on decomposition, and odor and color changes that occurred with heating of the nicotine salts are the basis for the predictions of the thermal stability of each nicotine salt. Detailed thermal analyses, such as differential thermal analysis or thermal gravimetric analysis, are currently being conducted and results will be published in the future. The predicted order of thermal stability for the salts (from least to most) is: acetate $<$ galacturonate $<$ alginate $<$ tannate $<$ tartrate $<$ salicylate $<$ ditoluoyltartrate.

\section{Analysis of the tobacco and smoke chemistry of $2 R 1$ \\ Reference cigarettes containing exogenous nicotine, nicotine salts and $\mathrm{N}^{\prime}$-formylnornicotine}

A set of eleven different non-filtered cigarettes was prepared employing tobacco from 2R1 Reference cigarettes in the 2R1 Reference cigarette configuration $(85-\mathrm{mm}$ length, $\sim 1.0-1.1 \mathrm{~g})$. The $2 \mathrm{R} 1$ Reference cigarette was the control. In each of the other ten cigarettes (Table 2), approximately $20-40 \mathrm{mg}$ of nicotine $(d$ or $l)$, a nicotine salt, or $N$-formylnornicotine was added as described previously. The average weight of each different cigarette was measured. The tobacco from each cigarette was analyzed for nicotine, nornicotine, anabasine and anatabine and the concentration of each alkaloid was recorded in Table 3. The amount of total nicotine available within each cigarette in the set was calculated (18.5-38.5 mg per $85-\mathrm{mm} \mathrm{rod})$. The range in total nicotine available for delivery based on a $23-\mathrm{mm}$ butt length was $13.5-34.1 \mathrm{mg}$ per $62-\mathrm{mm}$ rod that was consumed during FTC smoking. The eleven cigarettes were submitted for standard FTC smoke analysis. All cigarettes were smoked to a $23-\mathrm{mm}$ butt length. The puff count, total particulate matter (TPM), carbon monoxide (CO), and carbon dioxide $\left(\mathrm{CO}_{2}\right)$ remained relatively constant. The mainstream smoke nicotine yield ranged from $2.24-5.49 \mathrm{mg}$ per cigarette. Apparent nicotine transfer efficiencies were calculated as mainstream smoke nicotine divided by the amount of nicotine in the portion of the cigarette smoked multiplied by 100 . The apparent nicotine transfer efficiency values ranged from $12.5-25.0$ percent, averaging 17.8 percent, as shown in Table 4. Table 6 presents the results of regression analysis for this experimental series, predicting FTC smoke nicotine yields from the nicotine available in the $62-\mathrm{mm}$ tobacco rod consumed. Model no. 1 , which includes an intercept term, shows that the intercept is not significantly different from zero, with $p$ $=0.63$. Accordingly, model no. 2 with a zero-intercept was fit, resulting in an overall estimate of the apparent nicotine transfer efficiency of $17.5 \%$ for this experimental series. This is consistent with the confidence interval for the mean transfer efficiency $(15.5 \%, 20.0 \%)$ presented in Table 4. Figure 1 shows this regression model with the observed values for this series, along with a line for the second series of single grade "Tobacco Type" test cigarettes, discussed below.

Figure 1 shows considerable scatter about the regression line that may be due to the way the cigarettes were prepared (hand-made in some cases), the varied thermal stability of each nicotine salt, or the enantiomeric form of nicotine in the salt. The scatter is also a reflection of the slight differences in puff count between cigarettes. Table 4 indicates that the higher molecular weight, resinous gum and amorphous nicotine salts (nicotine alginate, nicotine tannate, and nicotine galacturonate) had apparent nicotine efficiencies less than the regression "average" value, indicating that less of the available nicotine in/on the tobacco may have been delivered to mainstream smoke. The apparent nicotine transfer efficiency for $l$ nicotine acetate (predicted to be the least stable nicotine salt) and the stable crystalline solid nicotine salt, $l$-nicotine salicylate, were close to the regression "average" value and were similar in smoke nicotine yield characteristics to the 2R1 and the cigarette with added $N^{\prime}$-formylnornicotine, both having no added nicotine. Interestingly, the 2R1 cigarettes prepared with either neat $d$ - or $l$ nicotine appear to have different smoke nicotine yield characteristics. The cigarette with neat $l$-nicotine appears to have yielded nicotine less efficiently to mainstream 


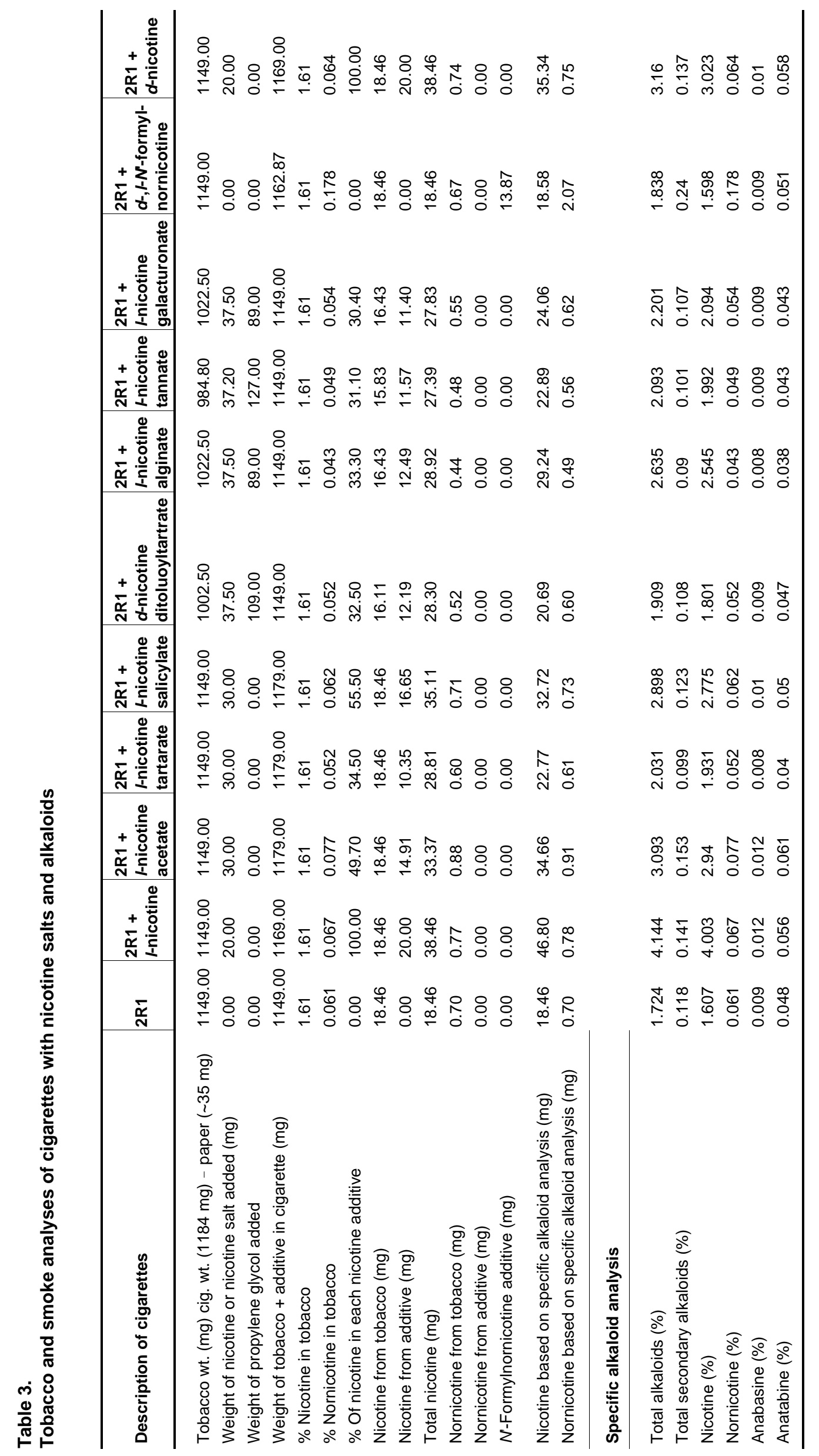




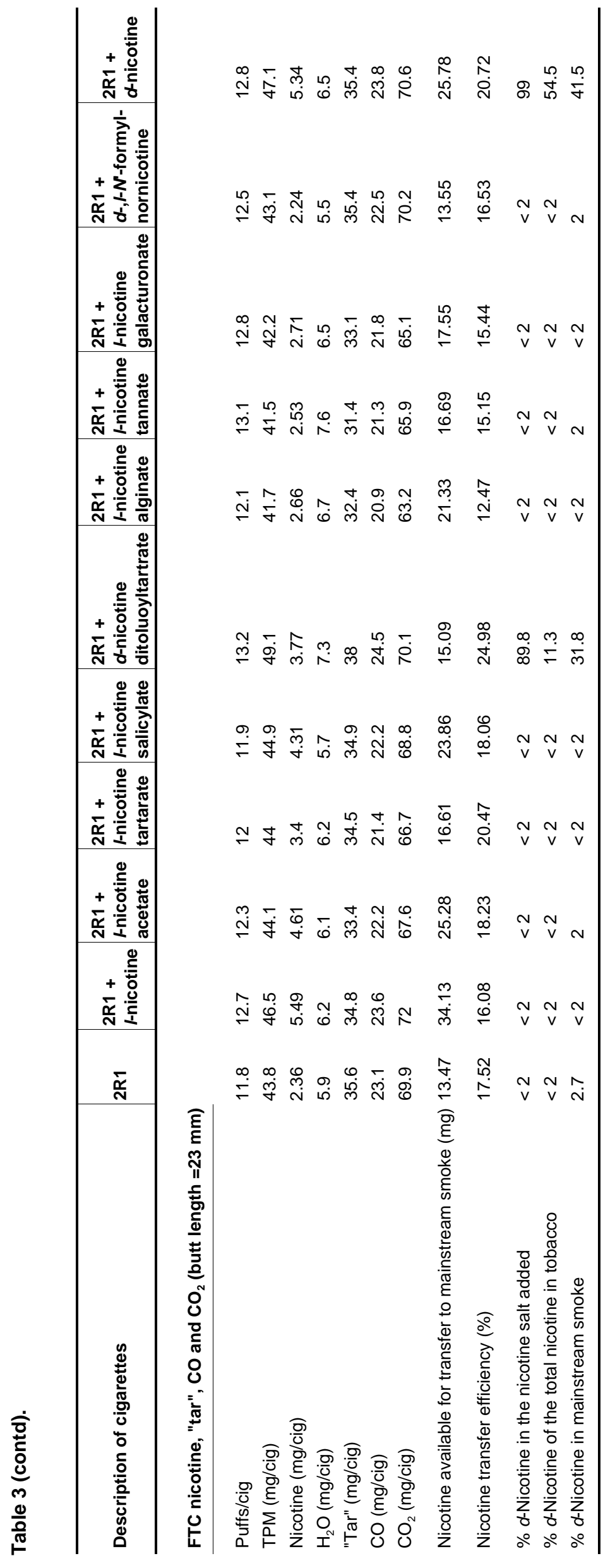


Table 4.

Apparent nicotine transfer efficiency and predicted values

\begin{tabular}{|c|c|c|c|c|c|}
\hline & $\begin{array}{c}\text { Nicotine } \\
(\mathrm{mg}) / \text { tobacco } \\
\text { burnt (mg) }\end{array}$ & $\begin{array}{c}\text { Nicotine in } \\
\text { MS smoke } \\
(\mathrm{mg} / \mathrm{cig})\end{array}$ & $\begin{array}{c}\text { Nicotine } \\
\text { transfer } \\
\text { efficiency (\%) } \\
\end{array}$ & $\begin{array}{c}\text { 2R1 model predicted } \\
\text { smoke nicotine } \\
(17.5 \% \text { eff. })\end{array}$ & $\begin{array}{l}\text { Observed - } \\
\text { predicted }\end{array}$ \\
\hline \multicolumn{6}{|l|}{ Series 1 - $2 \mathrm{R} 1$ with additive } \\
\hline No additive & 13.47 & 2.36 & 17.5 & 2.36 & 0.00 \\
\hline Neat $/$-nicotine & 34.13 & 5.49 & 16.1 & 5.97 & -0.48 \\
\hline I-Nicotine acetate & 25.28 & 4.61 & 18.2 & 4.42 & 0.19 \\
\hline I-Nicotine tartrate & 16.61 & 3.40 & 20.5 & 2.91 & 0.49 \\
\hline I-Nicotine salicylate & 23.86 & 4.31 & 18.1 & 4.18 & 0.13 \\
\hline$d$-Nicotine ditoluoyltartrate & 15.09 & 3.77 & 25.0 & 2.64 & 1.13 \\
\hline I-Nicotine alginate & 21.33 & 2.66 & 12.5 & 3.73 & -1.07 \\
\hline I-Nicotine tannate & 16.69 & 2.53 & 15.2 & 2.92 & -0.39 \\
\hline I-Nicotine galacturonate & 17.55 & 2.71 & 15.4 & 3.07 & -0.36 \\
\hline$d-I-I$-FormyInornicotine & 13.55 & 2.24 & 16.5 & 2.37 & -0.13 \\
\hline Neat $d$-nicotine & 25.78 & 5.34 & 20.7 & 4.51 & 0.83 \\
\hline Average & & & 17.8 & & \\
\hline Std. dev. & & & 3.4 & & \\
\hline $95 \% \mathrm{Cl}$ for mean & & & $(15.5,20.0)$ & & \\
\hline \multicolumn{6}{|l|}{ Series 2 - Single grade cigarettes } \\
\hline Lower stalk flue-cured & 17.71 & 3.08 & 17.4 & & \\
\hline Upper stalk flue-cured & 25.69 & 4.56 & 17.8 & & \\
\hline Lower stalk Burley & 21.40 & 3.68 & 17.2 & & \\
\hline Upper stalk Burley & 28.53 & 4.08 & 14.3 & & \\
\hline Oriental & 6.80 & 1.51 & 22.2 & & \\
\hline Expanded flue-cured stems & 3.95 & 0.32 & 8.1 & & \\
\hline $\mathrm{CO}_{2}$ exp. flue-cured / Burley tobacco & 10.08 & 2.21 & 21.9 & & \\
\hline Recon. tobacco sheet 1 & 7.24 & 0.83 & 11.5 & & \\
\hline Recon. tobacco sheet 2 & 7.38 & 0.75 & 10.2 & & \\
\hline Recon. tobacco sheet 3 & 8.94 & 1.05 & 11.7 & & \\
\hline Average & & & 15.2 & & \\
\hline Std. dev. & & & 4.9 & & \\
\hline $95 \% \mathrm{Cl}$ for mean & & & $(11.8,18.7)$ & & \\
\hline$t$-Test : series means equal $p=$ & & & 0.1720 & & \\
\hline
\end{tabular}

smoke but in a similar manner to the higher molecular weight amorphous/gum nicotine salts. $d$-Nicotine, $l$ nicotine tartrate and the ditoluoyltartrate salt of $d$ nicotine appear to have yielded nicotine to mainstream smoke more efficiently than $l$-nicotine or the other previously mentioned salts of $l$-nicotine. The average nicotine transfer efficiency from these data is about $18 \%$.

\section{Analysis of the tobacco and smoke chemistry of single grade cigarettes}

Table 5 gives physical data on cigarettes and chemical data on the tobacco and smoke from a series of single grade cigarettes prepared for determination of apparent nicotine transfer efficiency. There was a considerable range in the physical, tobacco and smoke data collected on this series of cigarettes. The apparent nicotine transfer efficiency for each cigarette was calculated and is presented in Table 4. The range in apparent nicotine transfer efficiency was $8.1-22.2 \%$. These data are also shown plotted in Figure 1. Table 6 presents the results of regression analysis as before, and shows that the intercept was not significantly different from zero (Model no. 3) with $p=0.69$. The subsequent no-intercept model (Model no. 4) has a slope of 0.162 , resulting in an overall estimate of $16.2 \%$ for apparent nicotine transfer efficiency for this experimental series. Again this is consistent with the $95 \%$ confidence interval (CI) for the mean transfer efficiency $(11.8 \%, 18.7 \%)$ presented in Table 4. 


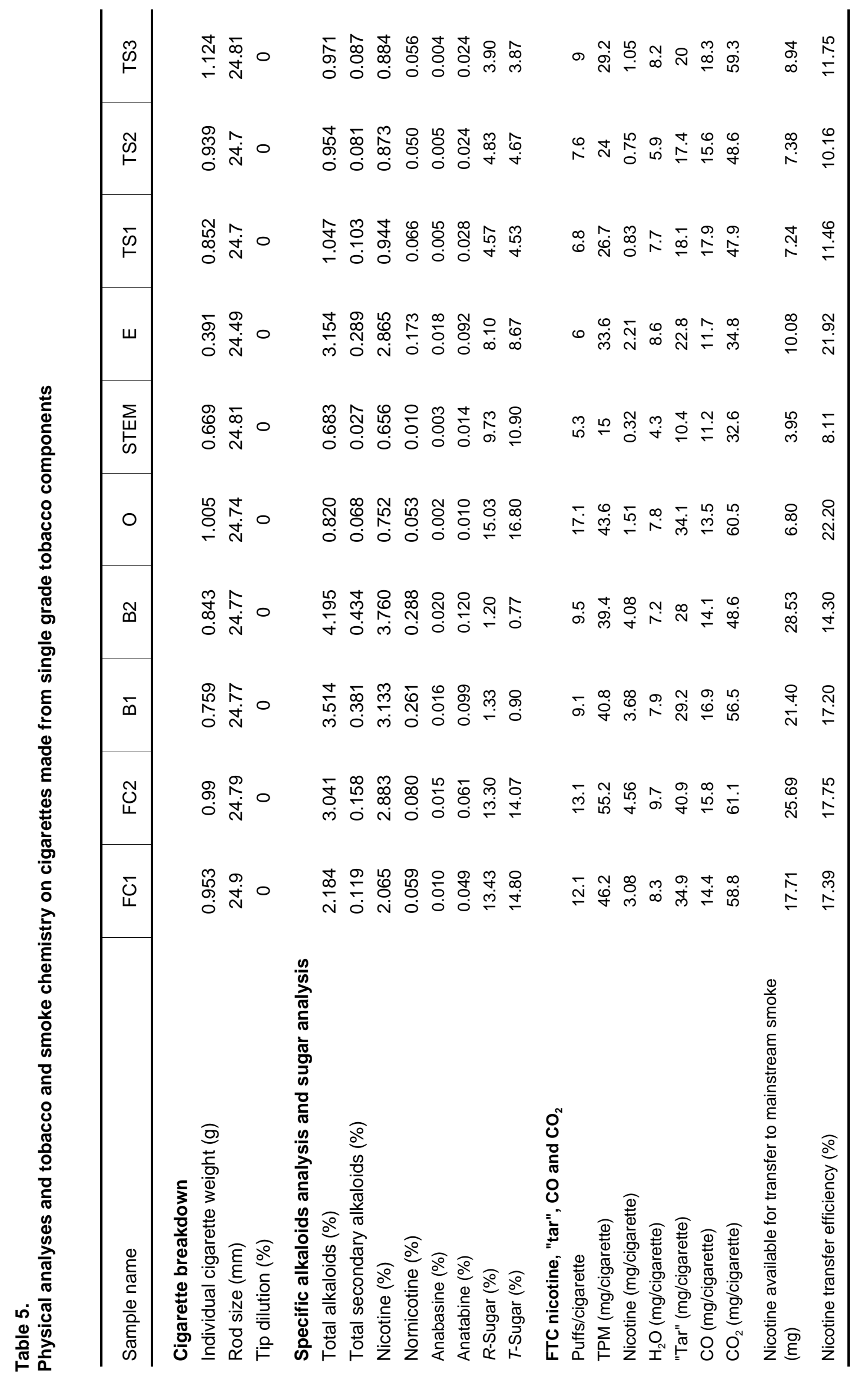


Table 6.

Transfer efficiency of nicotine from tobacco types and nicotine salts - comparison of regression models

\begin{tabular}{|c|c|c|c|c|c|c|c|c|c|}
\hline No. & Model & Data & $\mathrm{R}^{2}$ & Std. err. & Type & Intercept & Slope & $H_{0}$ & $P$-Value \\
\hline 1 & Nicotine salt & All & 0.734 & 0.653 & Nic. salt & 0.3384 & 0.1598 & Int. $=0$ & 0.63 \\
\hline 2 & Nicotine salt (int. $=0$ ) & All & 0.726 & 0.628 & Nic. salt & 0 & 0.1751 & & \\
\hline 3 & Tobacco & All & 0.926 & 0.445 & Tobacco & -0.1104 & 0.1683 & Int. $=0$ & 0.69 \\
\hline 4 & Tobacco (int. = 0) & All & 0.924 & 0.424 & Tobacco & 0 & 0.1624 & & \\
\hline \multirow[t]{2}{*}{5} & 2 Lines & All & 0.881 & 0.565 & Tobacco & -0.1104 & 0.1683 & Slope 1 = Slope 2 & 0.81 \\
\hline & & & & & Nic. salt & 0.3384 & 0.1598 & Int. $1=\operatorname{lnt} .2$ & 0.52 \\
\hline \multirow[t]{2}{*}{6} & 2 Lines (int. $=0$ ) & All & 0.878 & 0.541 & Tobacco & 0 & 0.1624 & Slope 1 = Slope 2 & 0.34 \\
\hline & & & & & Nic. salt & 0 & 0.1751 & & \\
\hline 7 & 1 Line & All & 0.873 & 0.554 & All & -0.0423 & 0.1728 & Int. $=0$ & 0.88 \\
\hline 8 & 1 Line (int. = 0) & All & 0.872 & 0.540 & All & 0 & 0.1707 & & \\
\hline
\end{tabular}

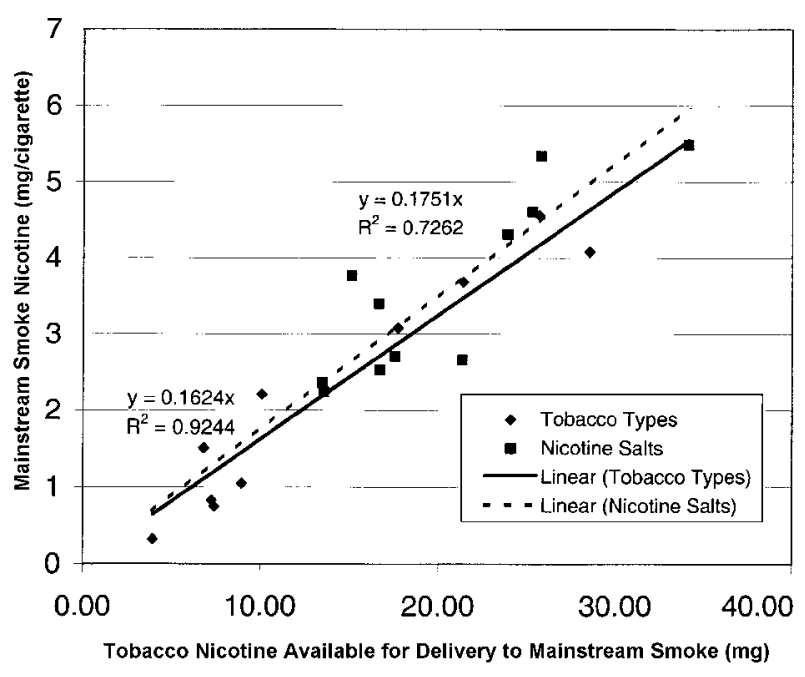

Figure 1.

Smoke nicotine vs. tobacco nicotine available for delivery to mainstream smoke

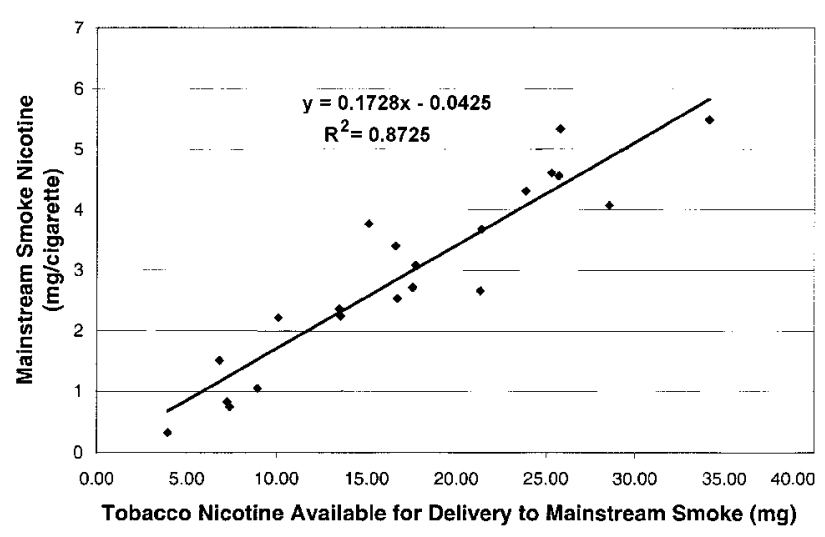

Figure 2.

Smoke nicotine vs. tobacco nicotine available for delivery to mainstream smoke (all data)
As both sets of cigarettes were non-filtered and were of similar construction, except for length, the data series for determination of apparent nicotine transfer efficiency were combined. A set of regression models were fit to the combined data to determine if the slopes were significantly different for the two series, and if the intercept was significantly different from zero. Models no. 5 and no. 6, in Table 6, present results for models that fit separate slopes for the two series and compare them. Results for Model no. 5, which fit separate non-zero intercepts, showed that the slopes were not different $(p=0.81)$ and the intercepts were not different $(p=0.52)$. Model no. 6, which fits no-intercept models, also found that the slopes were not different $(p=0.34)$. These results provided further justification for combining the two experimental series. Model no. 7 fit a single line with an intercept to the combined data, and again the intercept was not significantly different from zero $(p=0.88)$. Model no. 8 shows the slope estimate is 0.171 for a zero-intercept model, for an overall estimated transfer efficiency of $17.1 \%$. Figure 2 is a plot of the tobacco nicotine available for delivery to mainstream smoke $v s$. the FTC smoke nicotine yield for the combined data set with the zero-intercept model. The results of this analysis indicate that endogenous nicotine and nicotine in the form of nicotine salts all have apparent transfer efficiencies that are not statistically different from one another when treated as separate groups.

Analysis of the tobacco and smoke chemistry of $2 R 1$

Reference cigarettes and TS1 cigarettes containing exogenous $\mathrm{d}$ - and l-nicotine

Another experiment was conducted to test the hypothesis that $d$-and $l$-nicotine have the same apparent nicotine transfer efficiency. Two types of cigarettes (2R1 and TS1 cigarettes) containing a range of $d$-nicotine and $l$-nicotine 


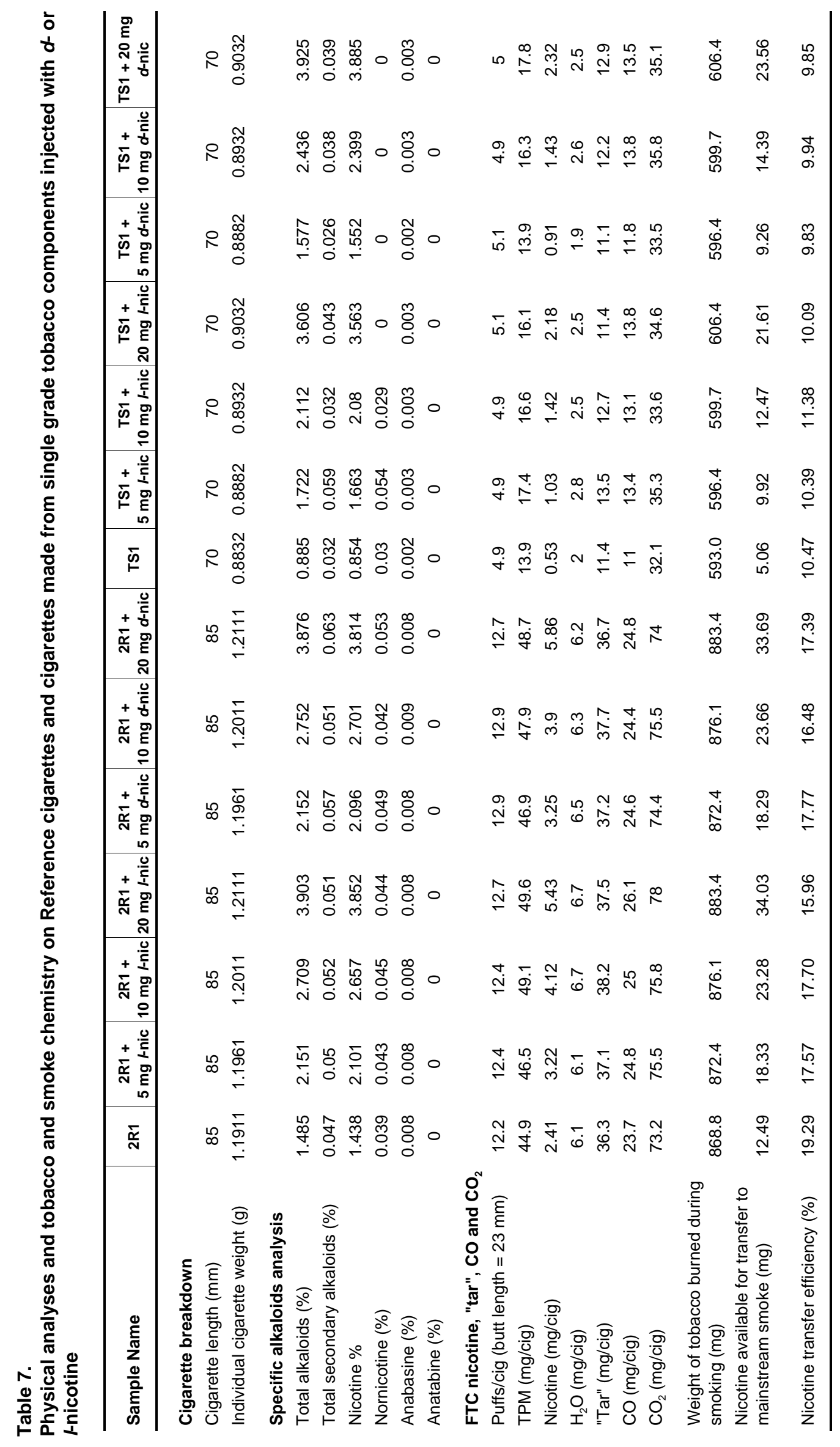


Table 8.

Data on 2R1 Reference cigarette and single grade cigarettes injected with $d$ - or l-nicotine for calculation of mainstream smoke nicotine transfer efficiency

\begin{tabular}{|c|c|c|c|}
\hline Cigarette types & $\begin{array}{l}\text { Nicotine }(\mathrm{mg}) / \\
\text { tob. burnt }(\mathrm{mg})\end{array}$ & Smoke nicotine $(\mathrm{mg})$ & $\begin{array}{c}\text { Smoke nicotine } \\
\text { transfer efficiency } \\
(\%)\end{array}$ \\
\hline 2R1 Reference cigarette (2R1) & 12.49 & 2.41 & 19.29 \\
\hline 2R1 with $5 \mathrm{mg} /$-nicotine added & 18.33 & 3.22 & 17.57 \\
\hline 2R1 with $10 \mathrm{mg}$ /-nicotine added & 23.28 & 4.12 & 17.70 \\
\hline 2R1 with $20 \mathrm{mg}$ l-nicotine added & 34.03 & 5.43 & 15.96 \\
\hline 2R1 with $5 \mathrm{mg} d$-nicotine added & 18.29 & 3.25 & 17.77 \\
\hline 2R1 with $10 \mathrm{mg} d$-nicotine added & 23.66 & 3.90 & 16.48 \\
\hline 2R1 with $20 \mathrm{mg} d$-nicotine added & 33.69 & 5.86 & 17.39 \\
\hline Average & & & 17.45 \\
\hline Standard deviation & & & 1.06 \\
\hline Reconstituted tobacco sheet 1 (TS1) & 5.06 & 0.53 & 10.47 \\
\hline TS1 with $5 \mathrm{mg} /$-nicotine added & 9.92 & 1.03 & 10.39 \\
\hline TS1 with $10 \mathrm{mg}$ l-nicotine added & 12.47 & 1.42 & 11.38 \\
\hline TS1 with $20 \mathrm{mg}$ l-nicotine added & 21.61 & 2.18 & 10.09 \\
\hline TS1 with $5 \mathrm{mg} d$-nicotine added & 9.26 & 0.91 & 9.83 \\
\hline TS1 with $10 \mathrm{mg} d$-nicotine added & 14.39 & 1.43 & 9.94 \\
\hline TS1 with $20 \mathrm{mg} d$-nicotine added & 23.56 & 2.32 & 9.85 \\
\hline Average & & & 10.24 \\
\hline Standard deviation & & & 0.55 \\
\hline
\end{tabular}

were prepared. These two cigarettes were chosen because they inherently have a large difference in endogenous nicotine and because they have a large difference in burn rates $(30,44)$. The data in Table 7 illustrate that the exogenously injected nicotine ( $d$ - or l-nicotine) was applied at three distinct levels on both sets of cigarettes. The puff count, FTC "tar", $\mathrm{CO}$ and $\mathrm{CO}_{2}$ yields for cigarettes within each set were relatively constant. The mainstream smoke nicotine yield increased with the level of exogenously applied $d$ - or $l$-nicotine. Table 8 is a summary of data used to calculate the nicotine transfer efficiencies for the cigarettes of this test series. The nicotine transfer efficiency for the 2R1 Reference cigarettes injected with exogenous nicotine varied between $16.0-19.3 \%$ with an average value of $17.5 \%$. The nicotine transfer efficiency for the TS1 cigarettes varied between $9.8-11.4 \%$ with an average value of $10.3 \%$. The mainstream nicotine transfer efficiencies for these cigarettes (2R1 and TS1) were similar to the values previously discussed (Tables 3 and 5) and reflect differences in the amount of tobacco burnt during the puff. The 2R1 Reference cigarette had a static burn rate of approximately $3.6 \mathrm{~mm} / \mathrm{min}(30)$ and a puff count of approximately 12.5 while the TS1 cigarettes had a static burn rate of approximately $7.2 \mathrm{~mm} / \mathrm{min}$ and a puff count of about 5 (44). It should be noted that the cigarettes of this experiment were smoked to a butt length of $23 \mathrm{~mm}$ and are different from the previous experiments of this report. As a result, the milligrams of nicotine in the tobacco burned per cigarette, the FTC smoke nicotine and the calculated nicotine transfer efficiencies noted in Tables 7 and 8 are slightly higher than those in Tables 3 and 5. Table 9 is a comparison of regression models predicting mainstream smoke yield from nicotine available in tobacco. As before, the slope of a zero-intercept model estimates the nicotine transfer efficiency. For each of the 2R1 and TS1 cigarettes, models were fit to the control cigarette and the test cigarettes with only $d$ - or $l$ - nicotine added. After these showed that the intercept was not significant, a model with a zero-intercept was fit and the slopes were compared with a $t$-test. These slopes were 0.169 and 0.174 for the $l$ - and $d$-nicotine added 2R1 cigarettes and 0.104 and 0.099 for the $l$ - and $d$-nicotine added TS1 cigarettes, not different for either 2R1 or TS1 when compared with a $t$-test. Figure 3 presents these data with the regression line for the 2R1 cigarettes, while Figure 4 presents similar information for the TS1 cigarettes. Combining the data for the $l$-and $d$-nicotine-added cigarettes, results in overall slopes of 0.170 for the $2 \mathrm{R} 1$ cigarettes and 0.101 for the TS1 cigarettes, each after determining the intercept was not significant. However, when these slopes are compared with a $t$-test or by combining the data and fitting a model with two lines to compare slopes, the slopes are significantly different $(p<0.0001)$.

Figure 5 is a plot of both the 2R1 and the TS1 combined data sets with regression models. The difference in 
Table 9.

Transfer efficiency of $I$ - and $d$-nicotine from 2R1 and TS1 cigarettes, comparison of regression models

\begin{tabular}{|c|c|c|c|c|c|c|c|c|c|}
\hline No. & Model & $N$ & $\mathrm{R}^{2}$ & Std. err. & Intercept & Slope & SE (Slope) & $H_{0}$ & $P$-Value \\
\hline 1 & 2R1 I-nicotine & 4 & 0.994 & 0.122 & 0.6814 & 0.1413 & 0.0077 & Int. $=0$ & 0.06 \\
\hline 2 & 2R1 I-nicotine (int. =0) & 4 & 0.952 & 0.284 & 0 & 0.1687 & 0.0061 & & \\
\hline 3 & 2R1 d-nicotine & 4 & 0.989 & 0.189 & 0.2826 & 0.1621 & 0.0121 & Int. $=0$ & 0.42 \\
\hline 4 & 2R1 $d$-nicotine (int. $=0$ ) & 4 & 0.984 & 0.189 & 0 & 0.1735 & 0.0040 & I Slope $=d$ Slope $($ int. $=0)$ & 0.53 \\
\hline 5 & 2R1 1 Line & 7 & 0.983 & 0.179 & 0.4600 & 0.1525 & 0.0091 & Int. $=0$ & 0.09 \\
\hline 6 & 2R1 1 Line (int. = 0) & 7 & 0.968 & 0.223 & 0 & 0.1703 & 0.0034 & & \\
\hline 7 & TS1 l-nicotine & 4 & 0.989 & 0.090 & 0.0677 & 0.0997 & 0.0075 & Int. $=0$ & 0.58 \\
\hline 8 & TS1 l-nicotine (int. = 0) & 4 & 0.986 & 0.081 & 0 & 0.1041 & 0.0030 & & \\
\hline 9 & TS1 $d$-Nicotine & 4 & 0.999 & 0.015 & 0.0265 & 0.0973 & 0.0011 & Int. $=0$ & 0.24 \\
\hline 10 & TS1 $d$-Nicotine (int. $=0$ ) & 4 & 0.999 & 0.019 & 0 & 0.0989 & 0.0006 & ISlope $=d$ Slope $($ int. $=0)$ & 0.16 \\
\hline 11 & TS1 1 Line & 7 & 0.990 & 0.073 & 0.0639 & 0.0974 & 0.0044 & Int. $=0$ & 0.38 \\
\hline 12 & TS1 1 Line (int. = 0) & 7 & 0.988 & 0.073 & 0 & 0.1012 & 0.0018 & $\begin{array}{c}\text { 2R1 Slope }=\text { TS1 Slope } \\
\quad(\text { int. }=0)\end{array}$ & 0.0001 \\
\hline \multirow[t]{2}{*}{13} & $\begin{array}{l}\text { 2R1 vs. TS1 } 2 \text { Lines } \\
\text { (int. = 0) }\end{array}$ & 14 & 0.991 & 0.166 & 0 & 0.1703 & 0.0025 & $\begin{array}{c}\text { 2R1 Slope }=\text { TS1 Slope } \\
\quad \text { (int. = 0) }\end{array}$ & 0.0001 \\
\hline & & & & & 0 & 0.1012 & 0.0041 & & \\
\hline
\end{tabular}

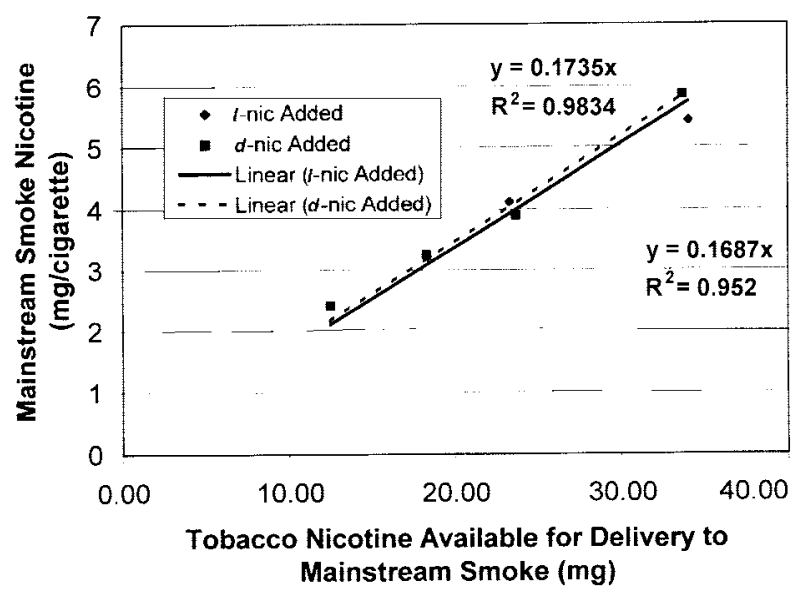

Figure 3.

Smoke nicotine vs. tobacco nicotine available for delivery to mainstream smoke - $2 R 1$

nicotine transfer efficiency is believed to be largely due to the burn rate for the different cigarettes. Further experiments are in progress to investigate the effects of burn rates in individual tobacco types on nicotine transfer efficiency.

Determination of d-nicotine in the tobacco and mainstream smoke of $2 R 1$ Reference cigarettes containing exogenous nicotine, nicotine salts and $\mathrm{N}^{\prime}$-formylnornicotine

An additional objective of this work was to determine if cigarettes prepared with exogenous levels of nicotine in

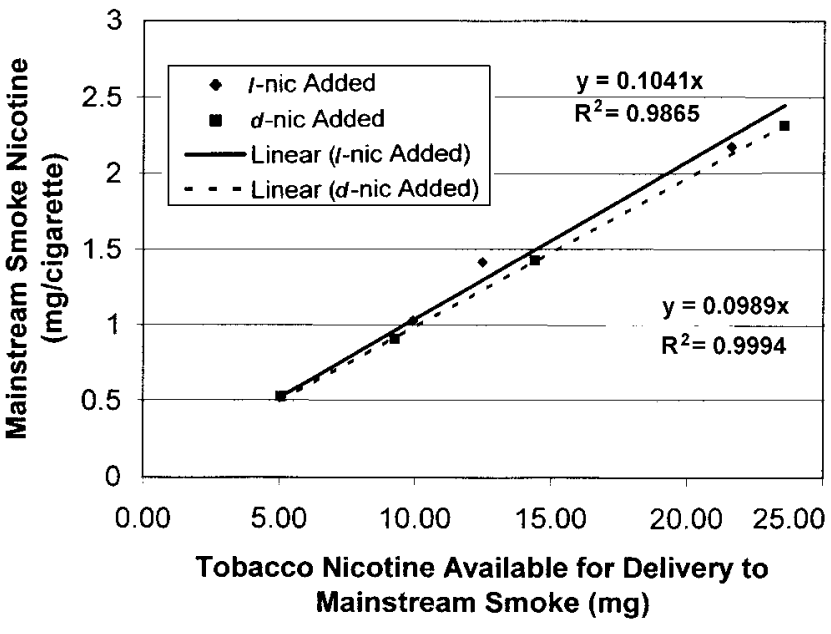

Figure 4.

Smoke nicotine vs. tobacco nicotine available for delivery to mainstream smoke - TS1

the form of neat nicotine or nicotine salts increased the level of $d$-nicotine in mainstream smoke. To test this hypothesis, a chiral-gas chromatographic technique (previously described) was employed to determine the enantiomeric purity of the nicotine and nicotine salts used in these experiments. Additionally, the vials used in the FTC smoke analysis for determination of nicotine and water in the cigarette smoke condensate were reanalyzed by the same chiral gas chromatographic technique. The percentage of $d$-nicotine in the sample of $d$-nicotine from T. D. C. Research was $99 \%$. The percentage of $d$-nicotine in the sample of $d$-nicotine ditoluoyltartrate from Sigma 


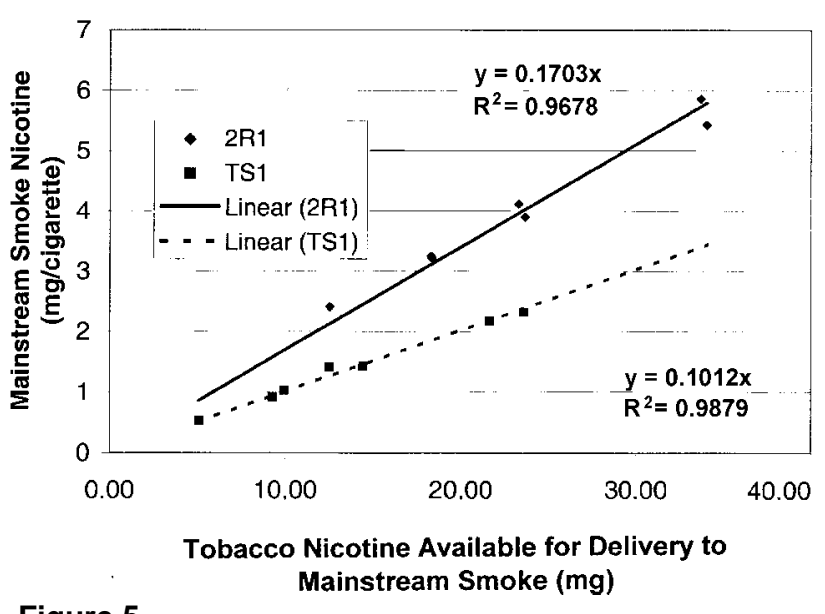

Figure 5.

Smoke nicotine vs. tobacco nicotine available for delivery to mainstream smoke - 2R1 vs. TS1

was $89 \%$ (Table 3 ). The percentage of $d$-nicotine in the total tobacco nicotine was $<2 \%$ for all samples except the samples with neat $d$-nicotine and the sample containing $d$ nicotine ditoluoyltartrate. In these two samples of tobacco the percentages of $d$-nicotine were $54.5 \%$ and $11.3 \%$, respectively (Table 3 ). The percentage of $d$-nicotine in the total mainstream smoke nicotine was approximately $2 \%$ for all samples, except the samples with neat $d$-nicotine and the sample containing $d$-nicotine ditoluoyltartrate. In these two samples the percentages of $d$-nicotine in mainstream smoke were $31.8 \%$ and $41.5 \%$, respectively (Table 3 ). These results suggest that the conversion of $l$-nicotine to $d$-nicotine via high temperature racemization does not occur during smoking.

\section{Test of bypotheses for the formation of $\mathrm{d}$-nicotine from exogenously applied d,1-N'-formylnornicotine}

Experiments were also performed to determine if exogenous $d, l$ - $N$-formylnornicotine applied to tobacco would be reduced to $d, l$-nicotine during the smoking process, or thermally decompose to $d$, $l$-nornicotine and react with methyl radicals to yield an enhanced level of $d$-nicotine in mainstream smoke.

$N$-Acyl alkaloids are produced during the growth and curing of tobacco. $N$-Formylnornicotine is a known tobacco and smoke alkaloid (37-40); $N$-formylnornicotine can decompose in tobacco to yield nornicotine in mainstream smoke $(36,39,40)$. In a reducing atmosphere such as is present behind the fire-cone of the burning cigarette, it may be possible to reduce $N$-formylnornicotine to nicotine. In prior work, CROOKS et al. (33) proposed that there are sufficient methyl radicals present in the tobacco smoke aerosol to react with $d$-nornicotine to produce $d$-nicotine in mainstream smoke. To test these hypotheses, $d, l-N$-formylnornicotine was synthesized (38, $41,42)$ and a high level $(13.9 \mathrm{mg})$ of $d, l-N$-formylnornicotine was applied to tobacco. Cigarettes were prepared and the level of $d$-nicotine in mainstream smoke was determined. Based on information in Table 2, the test ciga- rette with $d, l-N^{\prime}$-formylnornicotine had approximately the same yield of nicotine in mainstream smoke, the same apparent nicotine transfer efficiency and essentially the same level of $d$-nicotine $(<2 \%)$ in the total smoke nicotine. These results indicate that the proposed mechanism is not operative in the formation of $d$-nicotine in mainstream smoke.

\section{CONCLUSIONS}

The results of this study indicate that there is no difference in the transfer efficiency for salts of $d$ - and $l$-nicotine or for neat $d$ - and $l$-nicotine added to tobacco. The results also indicate that at the temperature of the burning cigarette, all of the nicotine salts tested transferred nicotine at similar efficiencies, regardless of the thermal stability of the nicotine salt. The results of this work indicate that the thermal stability of nicotine salts has no bearing on the racemization of nicotine and therefore on the yield of $d$ nicotine in mainstream smoke. Finally, the hypotheses tested for the formation of $d$-nicotine in mainstream smoke via reaction of methyl radicals with $d$-nornicotine or via reduction of $d, l-N$-formylnornicotine to form $d, l$ nicotine are not operative.

The mechanism generally believed to be true for the transfer of tobacco nicotine to smoke has been studied extensively (2) and involves the following aspects. First, when the cigarette is lit, tobacco reaches a very high temperature $700-950^{\circ} \mathrm{C}(3,20)$. At these temperatures, nicotine in the form of nicotine salts in the tobacco is converted to vapor phase, unionized nicotine or is pyrolyzed. Ionized nicotine cannot exist as a vapor and therefore the nicotine salts in tobacco decompose at these elevated temperatures (25). Almost instantaneously, the gases produced during combustion and pyrolysis begin to condense and form aerosol particles. Most of the unionized nicotine chemically reacts to form or reform nicotine salts. The concentration of organic acids in tobacco and tobacco smoke is in great excess compared to the concentration of organic bases in mainstream smoke (25). The formed aerosol particles are comprised of thousands of compounds including nicotine salts, unionized nicotine and other solids and gases (3). Very little unionized nicotine exists in the mainstream smoke of cigarettes (21-23).

During FTC smoke collection, a Cambridge pad traps $>99 \%$ of all aerosol particles. Vapor-phase materials pass through the pad. The amount of nicotine in the particulate phase compared to the total mainstream nicotine is $>97 \%(22,24)$.

Therefore, even if all the nicotine in the cigarette were in an unionized, neat form, the amount of FTC nicotine collected for a cigarette of this type would not change. This means that during the burning cigarette process, the unionized nicotine must get converted to nicotine salts that are trapped as particulate matter on the Cambridge pad. 
Several scientists have found that exogenously applied nicotine has a slightly higher transfer efficiency compared to endogenous nicotine $(13,19,43)$. HOUSEMAN found that $d-\left[2{ }^{\prime}-{ }^{14} C\right]$ nicotine di- $p$-toluoyltartrate applied to cigarettes had a higher transference of nicotine to mainstream smoke compared to endogenous $l$-nicotine (13). ARMITAGE, HOUSEMAN and TURNER (43) demonstrated that endogenous and exogenous nicotine had similar transfer efficiencies, with a slightly higher efficiency for the exogenous nicotine. JENKINS and COMES (19) showed that exogenously applied nicotine had about 4 percent greater transfer efficiency for exogenous nicotine vs. endogenous nicotine. The reported 4 percent difference was not considered meaningful as cigarette-to-cigarette variability would be expected to be greater than the differences found in transfer efficiency. As a result, JENKINS and COMES (19) concluded that for practical purposes the transfer efficiencies of exogenous ( $d$ - or $l$-nicotine) $v s$. endogenous nicotine (l-nicotine) were essentially the same.

Acknowledgements: The authors would like to acknowledge the work and support of Mr. C.D. McGee and Mrs. Milly Wong for helping to prepare many of the blends and cigarette protocepts tested in this report. The authors would also like to thank Dr. Jeffrey I. Seeman for his extensive help and guidance in the final preparation of this manuscript.

\section{REFERENCES}

1. Huber, G.L: Physical, chemical and biological properties of tobacco, cigarette smoke, and other tobacco products; Semin. Respir. Med. 10 (1989) 297-332.

2. Townsend, D.E: The effect of tobacco moisture on the removal of cigarette smoke by the tobacco rod; 37th Tob. Chem.Res Conf., Washington, DC, paper 27,1983; and: Baker, R.R.: Smoke chemistry; in: Tobacco: production, chemistry and technology; edited by D.L. Davis and M. T. Nielson, Blackwell Science Ltd., Oxford, 1999, 398-439, see p. 404.

3. Baker, R.R: Product formation mechanisms inside a burning cigarette; Prog. Energy Combustion Sci. 7 (1981) 135-153.

4. Jenkins, R.W. Jr: The use of nuclear radiation in chemical mechanistic studies; Proceedings of the International Conference on the Physical and Chemical Processes Occurring in a Burning Cigarette, R.J. Reynolds Tobacco Co, Winston-Salem, NC, 1987, pp. 155-228.

5. Jenkins, R.W. Jr., R.A. Comes, and R.T. Bass: The use of carbon-14 labeled compounds in smoke precursor studies - a review; Rec. Adv. Tob. Sci. (1976) 1-30.

6. Larson, P.S. and E.S. Harlow: Some current applications of carbon-14 to animal and human physiological research studies with tobacco and its constituents; Radioisot. Sci. Res. 3 (1958) 62-78.

7. Rustemeier, K and J.-J. Piadé: Determination of nicotine in mainstream and sidestream cigarette smoke; in: Analytical determination of nicotine and related compounds and their metabolites, edited by J.W. Gorrod and P.J. Jacob, III, Elsevier, Oxford, 1999, 489-529.

8. Schmeltz, I., A. Wenger, D. Hoffmann, and T.C. Tso: Chemical studies on tobacco smoke. 63. On the fate of nicotine during pyrolysis and in a burning cigarette; J. Agric. Food Chem. 27 (1979) 602-608.

9. Jenkins, R.W. Jr., R.H. Newman, and M.K. Chavis: Smoke distribution and mainstream pyrolytic composition of added ${ }^{14} \mathrm{C}$-menthol (U); Beitr. Tabakforsch. 5 (1970) 299-301.

10. Curran, J.G. and J.E. Kiefer: A method for measuring the elution of nicotine and total particulate matter from a cigarette filter; Beitr. Tabakforsch. 7 (1973) 29-35.

11. Newell, M.P, P.H. Latimer, and R.J. Haefele: The fate of oxalic, malic and citric acids in the smoke of cigarettes; 22nd Tob. Chem. Res. Conf., Richmond, VA, paper 24, 1968.

12. Davis, D.L., P.B. Bush, C. Grunwald, and P.L. Cornelius: Transfer of exogenously applied and endogenous alkaloids and sterols from tobacco to its smoke condensate; J. Agric. Food Chem. 25 (1977) 752-756.

13. Houseman, T.H.: Studies of cigarette smoke transfer using radioisotopically labelled tobacco constituents. Part II: The transference of radioisotopically labelled nicotine to cigarette smoke; Beitr. Tabakforsch. 7 (1973) 142-147.

14. Kobashi, Y., S. Sakaguchi, and M. Isawa: Combustion temperatures of some unblended cigarettes and the transfer of nicotine into cigarette smoke; Bull. Agr. Chem. Soc. Japan 24 (1960) 274-277.

15. Thornton, R.E. and S.R. Massey: Some effects of adding sugar to tobacco; Beitr. Tabakforsch. 8 (1975) $11-15$.

16. Tso, T.C. and J. Chaplin: Simple correlation and multiple regression among leaf characteristics, smoke components, and biological responses of bright tobaccos; USDA Tech. Bulletin No. 1551, 1977.

17. Perfetti, T.A.: Structural study of nicotine salts; Beitr. Tabakforsch. Int. 12 (1983) 43-54.

18. Betts, T.E.: Sugar in tobacco - its effect on smoke pH; Laboratory Prac. 30 (1981) 346-348.

19. Jenkins, R.W. Jr. and R.A. Comes: Exogenous vs. endogenous transfer of nicotine during smoking; Int. J. Appl. Radiation. Isot. 27 (1976) 323-324.

20. Wynder, E.L. and D. Hoffmann: Tobacco and tobacco smoke. Studies in experimental carcinogenesis. Academic Press, New York, NY, 1967, pp. 127-128, pp. 545-575.

21. Morie, G.P.: Fraction of protonated and unprotonated nicotine in tobacco smoke at various $\mathrm{pH}$ values; Tob. Sci. 16 (167) 1972. 
22. Lewis, D.A., I. Colbeck, and D.C. Mariner: Diffusion denuder method for sampling vapor-phase nicotine in mainstream tobacco smoke; Anal. Chem. 66 (1994) 3525-3527.

23. Lewis, D.A., I. Colbeck, and D.C. Mariner: Dilution of mainstream tobacco smoke and its effect upon the evaporative and diffusion of nicotine; Aerosol Sci. 26 (1995) 841-846.

24. Morie, G.P.: Computer program for the calculation of concentrations of chemical species present in tobacco smoke at various $\mathrm{pH}$ values; Technical Report from Filter Products Research Laboratory, Eastman Chemical Co., Kingsport, TN, FTR-14.

25. Seeman, J.I., J.A. Fournier, and J.B. Paine III: Thermal transfer of nicotine and nicotine salts to nicotine in the gas phase; J. Agric. Food Chem. 47 (1999) 5133-5145.

26. Stevens, N.A. and M.F. Borgerding: GC-AED studies of nicotine fate in a burning cigarette; Anal. Chem. 71 (1999) 2179-2185.

27. Perfetti, T.A., W.M. Coleman III, and W.S. Smith: Determination of mainstream and sidestream cigarette smoke components for cigarettes of different tobacco types and a set of Reference cigarettes; Beitr. Tabakforsch. Int. 18 (1998) 95-113.

28. Perkins, P.R. and C.R. Bales: Nicotine fortification of smoking products; U.S. Patent 3,861,400 to Imperial Tobacco Group Ltd., London, England, January 21, 1975.

29. Pillsbury, H.C., C.C. Bright, K.J. O'Connor and F.W. Irish: Tar and nicotine in cigarette smoke; J. Assoc. Off. Anal. Chem. 52 (1969) 458-462.

30. Diana, J.N., and A. Vaught: The research cigarette; The Tobacco and Health Research Institute, Lexington, KY, 1990.

31. Green, C.R. and A. Rodgman: The Tobacco Chemists' Research Conference: A half century forum for advances in analytical methodology of tobacco and its products; Rec. Adv. Tob. Sci. 22 (1996) 131-304.

32. Bowman, E.R., H. McKennis, Jr., and B.R. Martin: A convenient method for the preparation of racemic nicotine; Synth. Commun. 12 (87) (1982) 1-879.

33. Crooks, P.A., C.S. Godin, and W.F. Pool: Enantiomeric purity of nicotine in tobacco smoke condensate; Med. Sci. Res. 20 (1992) 879-880.

34. Perfetti, T.A. and W.M. Coleman, III: Chiral-gas chromatography-selected ion monitoring - mass selective detection analysis of tobacco materials and tobacco smoke; Beitr. Tabakforsch. Int. 18 (1998) $15-33$.
35. Perfetti, T.A. and W.M. Coleman, III: Chiral-gas chromatography-selected ion monitoring - mass selective detection analysis of secondary alkaloids in tobacco and tobacco smoke; Beitr. Tabakforsch. Int. 18 (1998) 35-42.

36. Tso, T.C.: Production, physiology, and biochemistry of tobacco plant; Ideal, Beltsville, MD, 1990, p. 428.

37. Piadé, J.J. and D. Hoffmann: Chemical studies on tobacco smoke, LXVII. Quantitative determination of alkaloids in tobacco by liquid chromatography; J. Liquid Chromatogr. 3 (1980) 1505-1515.

38. Warfield, A.H., W.D. Galloway, and A.G. Kallianos: Some new alkaloids from Burley tobacco; Phytochem. 11(1972) 3371-3375.

39. Schumacher, J.N., C.R. Green, F.W. Best, and M.P. Newell: Smoke composition - an extensive investigation of the water-soluble portion of cigarette smoke; J. Agric. Food Chem. 25 (1977) 310-320.

40. Snook, M.E., O.T. Chortyk, and R.F. Arrendale: Isolation and identification of $N^{\prime}$-acylalkaloids of cigarette smoke; Beitr. Tabakforsch. Int. 12 (1984) 227-243.

41. Burton, H.R., R.A. Andersen, P.D. Fleming, and L.R. Walton: Changes in chemical composition of burley tobacco during senescence and curing. 2. Acylated pyridine alkaloids; J. Agric. Food Chem. 36 (1988) 579-584.

42. Glenn, D.F. and W.B. Edwards III: Synthesis and mass spectrometry of some structurally related nicotinoids; J. Org. Chem. 43 (1978) 2860-2870.

43. Armitage, A., T. Houseman, and D. Turner: The transfer of exogenous and exogenous nicotine to mainstream cigarette smoke and its absorption into the blood of anesthetized cats; J. Expt. Physiol. 59 (1974) 55-61.

44. Norman, A.B., R.G. Hayworth, and T.A. Perfetti: Properties of tobacco related to cigarette burn rates; Accepted to Tob. Sci. (1999).

Address for correspondence:

Thomas A. Perfetti

R.J. Reynolds Tobacco Company

P.O. Box 1487

Winston-Salem, NC 27102-1487 